\title{
Adsorptive removal of polycyclic aromatic hydrocarbons by detritus of green tide algae deposited in coastal sediment
}

\author{
Cui Zhang ${ }^{\mathrm{a}, \mathrm{b}}$, Jian $\mathrm{Lu}^{\mathrm{a}, \mathrm{b}, \mathrm{c}, *}$, Jun $\mathrm{Wu}^{\mathrm{d}}$ \\ tory of Coastal Environmental Processes, YICCAS, Yantai, Shandong 264003, PR China \\ ${ }^{\mathrm{b}}$ University of Chinese Academy of Sciences, Beijing 100049, PR China \\ c Center for Ocean Mega-Science, Chinese Academy of Sciences, 7 Nanhai Road, Qingdao 266071, PR China \\ ' School of Resources and Environmental Engineering, Ludong University, Yantai, Shandong 264025, PR China
}

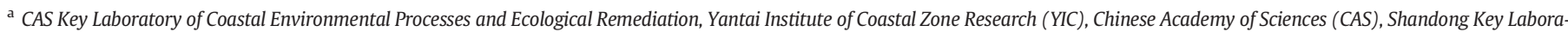

\section{H I G H L I G H T S}

- The adsorption of typical PAHs by Ulva prolifera detritus was firstly investigated.

- High adsorptive removal efficiency and low desorption rate of PAHs were observed.

- The maximum adsorption capacity of phenanthrene was $1.97 \mu \mathrm{g} \mathrm{g}^{-1}$.

- In situ monitoring using LCSM confirmed the adsorption of the PAHs on detritus.

- The adsorptive removal showed new natural remediation for coastal sediment with PAHs.

\section{G R A P H I C A L A B S T R A C T}

Trapped in algal detritus $=$ A new natural remediation?

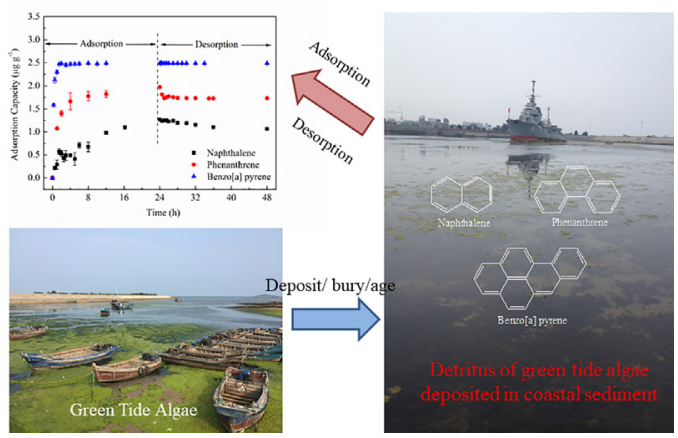

\section{A R T I C L E I N F O}

\section{Article history:}

Received 29 December 2018

Received in revised form 19 March 2019

Accepted 19 March 2019

Available online 20 March 2019

Editor: Filip M.G. Tack

\section{Keywords:}

Ulva prolifera

Detritus

Polycyclic aromatic hydrocarbons

Adsorptive removal

Natural remediation

Sediment

\begin{abstract}
A B S T R A C T
Rare information is available on the adsorptive removal of polycyclic aromatic hydrocarbons (PAHs) in the presence of algal detritus deposited in the coastal sediment during the outbreak of the green tide. The adsorptive removal of typical PAHs by Ulva prolifera (U. prolifera) detritus was firstly investigated since the algal detritus was of great importance for the biogeochemical cycle of coastal contaminants. The results showed that equilibrium adsorptive capacities of naphthalene, phenanthrene and benzo[a] pyrene on the U. prolifera detritus were 1.27, 1.97, and $2.49 \mathrm{mg} \mathrm{kg}^{-1}$, respectively, at the initial concentration of $10 \mu \mathrm{g} \mathrm{L}^{-1}$. The in situ monitoring using laser confocal scanning microscopy confirmed the adsorptive removal of PAHs by U. prolifera detritus. The adsorption of these PAHs was highly pH-dependent. The increase in salinity led to the increase in naphthalene removal rate, while the salinity showed scarce influence on the removal of phenanthrene and benzo[a] pyrene. There was a good linear relationship $\left(R^{2} \geq 0.9892\right)$ between the removal efficiency of PAHs and the initial concentration of PAHs. Slow desorption kinetics and low desorption rate $(<16 \%)$ indicated that the adsorptive removal of PAHs could be benign to the environment. These findings demonstrated that the occurrence of green tide could provide a new natural remediation approach for contamination of PAHs through the adsorptive removal by the detritus of green tidal algae deposited in the coastal sediment.
\end{abstract}

(c) 2019 Elsevier B.V. All rights reserved.

\footnotetext{
* Corresponding author at: CAS Key Laboratory of Coastal Environmental Processes and Ecological Remediation, Yantai Institute of Coastal Zone Research (YIC), Chinese Academy of Sciences (CAS), Shandong Key Laboratory of Coastal Environmental Processes, YICCAS, Yantai, Shandong 264003, PR China.

E-mail address: jlu@yic.ac.cn (J. Lu).
} 


\section{Introduction}

Ulva prolifera (U. prolifera) has been frequently involved in terrible green tides in the coastal areas. From 2007 onwards, green tides dominated by $U$. prolifera frequently flourish along the coastal regions of Jiangsu Province (China) (Liu et al., 2015), and then float northward with a fresh biomass of 100 million metric tons until land on seashore of Shandong Province, influencing the coastal ecosystems of north China. Additionally, $>1000$ transportation vehicles and 1600 fishing vessels were dispatched to clean up the massive bloom, causing an economic loss exceeding US \$100 million in 2008 (Zhang et al., 2013b). At the end of algae life circle, patches of dead biomass can deposit, embed, and be aged into the sediment (Turner, 2015). The algalderived nutrients and organic matter could be released during such process, leading to the increase in the concentrations of particulate organic nitrogen and organic carbon in water and sediments (Zhou et al., 2018). These processes are of great importance for the biogeochemical cycle of coastal contaminants. The algae possess higher ratio of surface to volume and different functional groups including the carboxyl, hydroxyl and sulphate groups, which provides them with the potential of substantially removing pollutants such as nutrients (nitrogen and phosphorus) (Fan et al., 2014; Li et al., 2016; Luo et al., 2012; Sun et al., 2015) and metals (Sarı and Tuzen, 2008a) from seawater. In many previous studies, the fresh algae were often dried (Gao et al., 2018) and/or modified by ferric chloride (Son et al., 2018), sulfuric acid (Xiong et al., 2013) and formaldehyde (Yang and Chen, 2008) to improve the surface physico-chemical characteristics of algal biomass for reinforcing their sorption performance. However, the influence of the natural detritus generated from natural green tidal algae on the attenuation of hazardous organic pollutants in coastal sediment has not been evaluated.

Known as a critical region of earth, the coastal zone is deeply influenced by the human activities (Wen et al., 2017). Coastal areas are especially vulnerable zones to anthropogenic polycyclic aromatic hydrocarbons (PAHs) which mainly originate from incomplete combustion of fossil fuels and oil spills (Sun et al., 2018). PAHs are highly lipophilic so as to carry toxicological significance to both aquatic organisms and humans via food chains (Luo et al., 2014; Zhang et al., 2017b). It has been pointed out that dead biomass of the algae might be more effective than living ones for the removal of toxic pollutants (Luo et al. 2014). The potential influence of the algal detritus on PAHs existing in aquatic ecosystems with low concentrations is poorly understood although algae serve as the primary producers in coastal and estuarine systems to play an important role in the fate of PAHs in these ecosystems (Zhang et al., 2017a).

Knowledge on adsorption and desorption mechanisms of PAHs is essential to reveal their fate and transport in aquatic environments. Mechanisms regarding adsorption of PAHs on various adsorbents mainly include the $\mathrm{H}$-bonding formation, the electron donor-acceptor interaction and the $\pi-\pi$ interaction (Yuan et al., 2010). However, information on adsorption mechanism by algae is very limited. Arias et al. (2017) found that physico-chemical partition processes played a predominant role in PAHs biosorption by marine algae Rhodomonas baltica. The similar result was also reported by Chen et al. (2011) who studied biosorption of PAHs by plant residues. They also found that polarity $[(\mathrm{O}+\mathrm{N}) / \mathrm{C}]$, aromaticity $(\mathrm{H} / \mathrm{C})$, and sugar content imposed important effects on sorptive behavior of the biosorbents (Chen et al., 2011). To the best of our knowledge, there is no report on the adsorption/desorption behaviors of PAHs on U. prolifera detritus deposited in coastal sediment. The algal detritus might be a significant contributor for removing PAHs in coastal sediments due to the accumulation of huge amounts of $U$. prolifera detritus in coastal sediments during the occurrence of green tide. Previous studies showed that 2- to 3-ring PAHs were predominant in seawater, 2- to 4-ring PAHs were abundant in suspended particulate matters, and PAHs with $>4$ rings were abundant in sediments (Khuman et al., 2018; Zhang et al., 2017b; Zhao et al., 2015). Therefore, naphthalene (Naph), phenanthrene (Phe) and benzo[a] pyrene (BaP) were selected as the representative 2-, 3-, and 5-ring PAHs to explore the environmental effects of $U$. prolifer detritus due to their frequent detection in the aquatic environments. The objectives of this work are to: (1) evaluate the efficiency of $U$. prolifera detritus on the potentially removing PAHs; (2) investigate the influences of environmental factors such as $\mathrm{pH}$, salinity and temperature on adsorptive removal of PAHs; and (3) clarify mechanisms and kinetics of the adsorption and desorption of PAHs on the detritus of typical green tide algae deposited in coastal sediment.

\section{Material and methods}

\subsection{Reagents and materials}

Naphthalene (Naph, 99.6\% purity) was provided by Dr. Ehrenstorfer $\mathrm{GmbH}$ (Augsburg, Germany). Phenanthrene (Phe, purity $>99.0 \%$ ) and benzo[a] pyrene (BaP, purity $>96.0 \%$ ) were purchased from Aladdin (Shanghai, China). Methanol, acetonitrile, n-hexane, and isopropyl alcohol were all HPLC grade. The stock solution of Naph $\left(100 \mathrm{mg} \mathrm{L}^{-1}\right)$, Phe (100 $\left.\mathrm{mg} \mathrm{L}^{-1}\right)$, and BaP $\left(100 \mathrm{mg} \mathrm{L}^{-1}\right)$ were prepared in methanol. Sodium hydroxide and hydrochloric acid were analytical reagents and used directly. The sediment with $U$. prolifera detritus were collected in July 2017 from the coast of Rushan city, China. In the laboratory, the algae detritus was cleaned with sterile seawater to remove the sediment, and then kept in freezer maintaining at $-20{ }^{\circ} \mathrm{C}$ for further experiments.

\subsection{Adsorption studies}

\subsubsection{Batch experiments}

The adsorptive experiments of the three PAHs by the detritus biomass under different environmental factors were conducted in $100 \mathrm{~mL}$ conical flask with stopper containing $80 \mathrm{~mL}$ sterilized seawater with relevant concentrations of three target PAHs (Naph, Phe or BaP) and the detritus of $U$. prolifera. The concentration of each target PAHs was $10.0 \mu \mathrm{g} \mathrm{L}^{-1}$ while that of the algal detritus was $4 \mathrm{~g} \mathrm{~L}^{-1}$. The flasks were shaken at rolling speed of $170 \mathrm{rpm}$ under a constant temperature $\left(20 \pm 0.5^{\circ} \mathrm{C}\right)$. After the reaction period, certain aliquots were sampled and centrifuged at $12000 \mathrm{rpm}$ for $6 \mathrm{~min}$ before ultra high performance liquid chromatography (UPLC) analysis. Two blank adsorptive experiments, one with the cultural media containing PAHs without $U$. prolifera detritus and another containing $U$. prolifera detritus without PAHs, were also conducted. All experiments were conducted in triplicate.

To explore the effect of $\mathrm{pH}$ on the adsorption process, the $\mathrm{pH}$ of reactant solutions was adjusted to $5.0-10.0$ using $\mathrm{NaOH}$ or $\mathrm{HCl}$ solutions before addition of $U$. prolifera detritus. Seawater with salinity of $32 \mathrm{~g} \mathrm{~L}^{-1}$ was diluted using ultrapure water to the salinity of 24 and $16 \mathrm{~g} \mathrm{~L}^{-1}$ for evaluating the effect of salinity on adsorption. To investigate the influence of initial concentration of target PAHs on removal efficiency, various initial concentrations of Naph $\left(5,10,20,50\right.$, and $\left.100 \mu \mathrm{g} \mathrm{L}^{-1}\right)$, Phe $\left(5,10,20,50\right.$, and $\left.100 \mu \mathrm{g} \mathrm{L}^{-1}\right)$ and $\operatorname{BaP}(1,5,10,20,50$, and $\left.100 \mu \mathrm{g} \mathrm{L}^{-1}\right)$ were obtained by diluting the stock solution of relevant PAHs with sterile seawater. In addition, temperature was adjusted by shaker to $10^{\circ} \mathrm{C}, 20^{\circ} \mathrm{C}$ and $30^{\circ} \mathrm{C}$ to observe the influence of temperature on adsorptive removal efficiency of PAHs by detritus of U. prolifera.

The adsorption efficiency and adsorption capacity $\left(\mathrm{q}_{\mathrm{t}}\right)$ of the three PAHs were calculated based on Eqs. (1) and (2), respectively.

$\operatorname{Removal}(\%)=\frac{\mathrm{C}_{0}-\mathrm{C}_{\mathrm{t}}}{\mathrm{C}_{0}} \times 100 \%$

$\mathrm{q}_{\mathrm{t}}=\frac{\left(\mathrm{C}_{0}-\mathrm{C}_{\mathrm{t}}\right) \mathrm{V}}{\mathrm{m}}$ 
where $C_{0}\left(\mu \mathrm{L} \mathrm{L}^{-1}\right)$ is the initial concentration of PAHs in liquid phase; $C_{t}$ $\left(\mu \mathrm{L} \mathrm{L}^{-1}\right)$ represents the concentration of liquid phase PAHs at time $\mathrm{t}(\mathrm{h})$; $\mathrm{V}(\mathrm{L})$ is the volume of PAHs solution used and $\mathrm{m}(\mathrm{g})$ is the mass of detritus biomass used.

The detritus-water partition coefficients $\left(K_{d w}\right)$ of the Naph, Phe and $\mathrm{BaP}$ are calculated as follows (Eq. (3)):

$K_{d w}=\mathrm{q}_{\mathrm{e}} / \mathrm{C}_{\mathrm{e}}$

where $\mathrm{q}_{\mathrm{e}}\left(\mathrm{mg} \mathrm{kg}^{-1}\right)$ is the adsorption capacity of PAHs at equilibrium; $\mathrm{C}_{\mathrm{e}}\left(\mu \mathrm{g} \mathrm{L}^{-1}\right)$ represents the concentration of liquid phase PAHs at equilibrium; $K_{d w}$ values were obtained from regression analysis of $\mathrm{q}_{\mathrm{e}}$ versus $\mathrm{C}_{\mathrm{e}}$ for five different initial PAHs levels.

\subsubsection{Adsorption kinetics}

The kinetics experiments were carried out at $20 \pm 0.5{ }^{\circ} \mathrm{C}$ to investigate the influence of contact time on PAHs adsorption. Samples were collected at given time intervals until the concentration of PAHs in the solution became constant. In addition, two typical kinetic models, pseudo first-order (Eq. (4)) and pseudo second-order (Eq. (5)) (Wen et al., 2012) were applied to describe the adsorption kinetics of PAHs. The equations are shown as follows:

$\ln \left(\mathrm{q}_{\mathrm{e}}-\mathrm{q}_{\mathrm{t}}\right)=\ln \mathrm{q}_{\mathrm{e}}-\mathrm{k}_{1} \mathrm{t}$

$\frac{\mathrm{t}}{\mathrm{q}_{\mathrm{t}}}=\frac{1}{\mathrm{k}_{2} \mathrm{q}_{\mathrm{e}}^{2}}+\frac{1}{\mathrm{q}_{\mathrm{e}}} \mathrm{t}$

where $\mathrm{q}_{\mathrm{e}}\left(\mathrm{mg} \mathrm{kg}^{-1}\right)$ is the equilibrium adsorption capacity; $\mathrm{k}_{1}\left(\mathrm{~h}^{-1}\right)$ and $\mathrm{k}_{2}\left(\mathrm{~g}(\mu \mathrm{g} \mathrm{h})^{-1}\right)$ are the rate constant of pseudo-first-order and pseudo-second-order adsorption, respectively.

In order to obtain further information on the mechanism of adsorption and potential rate controlling steps such as mass transport and diffusion control processes, an intraparticle diffusion model has been applied to predict the rate-controlling step, and its equation (Eq. (6)) can be expressed as follows:

$\mathrm{q}_{\mathrm{t}}=\mathrm{k}_{\mathrm{i}} \mathrm{t}^{0.5}+\mathrm{C}$

where $k_{i}\left(\mathrm{mg} \mathrm{kg}^{-1} \mathrm{~h}^{1 / 2}\right)$ is the intraparticle diffusion rate constant, and C is the intercept.

\subsubsection{Adsorptive isotherm experiment}

Temperature was adjusted by shaker to $10{ }^{\circ} \mathrm{C}, 20^{\circ} \mathrm{C}$ and $30{ }^{\circ} \mathrm{C}$ at $170 \mathrm{rpm}$ and an adsorptive isotherm curve was established by changing the concentrations of PAHs (Naph and Phe: 5-100 $\mathrm{g} \mathrm{L} \mathrm{L}^{-1}$, BaP: $1-100$ $\mu \mathrm{g} \mathrm{L}^{-1}$ ). The Langmuir model (Eq. (7)) and Freundlich model (Eq. (8)) were used for the mathematical description of the PAHs adsorption. The Langmuir isotherm is valid for monolayer adsorption onto a surface with a finite number of identical sites (Bulgariu and Bulgariu, 2012). As a modification of the Langmuir model, the Freundlich model is appropriate to describe binding adsorptive isotherms for organic contaminants onto inhomogeneous or rough adsorbent surfaces (i.e., algae) with multiple adsorption sites (Bhattacharya et al., 2010).

$\mathrm{q}_{\mathrm{e}}=\frac{\mathrm{Q}_{\mathrm{m}} \mathrm{k}_{\mathrm{L}} \mathrm{C}_{\mathrm{e}}}{1+\mathrm{k}_{\mathrm{L}} \mathrm{C}_{\mathrm{e}}}$

$\mathrm{q}_{\mathrm{e}}=\mathrm{k}_{\mathrm{F}} \mathrm{C}_{\mathrm{e}}{ }^{1 / \mathrm{n}}$

where $C_{e}\left(\mu g L^{-1}\right)$ represents the concentration of contaminant in the aqueous phase at equilibrium; $\mathrm{Q}_{\mathrm{m}}\left(\mathrm{mg} \mathrm{kg}^{-1}\right)$ is the maximum monolayer adsorption capacity; $\mathrm{K}_{\mathrm{L}}$ and $\mathrm{K}_{\mathrm{F}}\left(\mathrm{L} \mathrm{g}^{-1}\right)$ are the constants related to the Langmuir and Freundlich isotherms, respectively; $1 / n$ is the Freundlich exponent and an indicator of the site energy distribution of a sorbent (i.e. sorbent heterogeneity decreases as $n$ increases) (Bakir et al., 2014).
2.2.4. The isolation of algal fractions and their effects on adsorptive removal of PAHs

The algal fractions of the $U$. prolifera detritus were isolated according to Pieber et al. (Pieber et al., 2012) with some modifications. The detritus was lyophilized overnight using a freeze-dryer (FD-1A-50, Boyikang, Beijing, China). The lyophilized detritus (approximately $42 \%$ of original FW (fresh weight)) were powdered to extract lipid fraction and polysaccharides fraction by using an APLE 1000 accelerated solvent extraction apparatus (Titan, Beijing, China) equipped with $22 \mathrm{~mL}$ stainlesssteel extraction cells. The lipid fraction extraction was performed with the solvent mixtures n-hexane/isopropyl alcohol $(3: 2 \mathrm{v} / \mathrm{v})$ at $110{ }^{\circ} \mathrm{C}$ using a static extraction time of $180 \mathrm{~s}$ per cycle (two extraction cycles) at a pressure of $10 \mathrm{MPa}$ (preheat time: $120 \mathrm{~s}$, heating for $360 \mathrm{~s}$, flush volume: $40 \%$ of cell volume, purge time: $60 \mathrm{~s}$ ). The polysaccharides fraction was extracted under ultrapure water with preheating for $120 \mathrm{~s}$, heating for $300 \mathrm{~s}$, extraction at $15.0 \mathrm{MPa}$, static extraction for $300 \mathrm{~s}$, two extraction cycles, flush volume of $40 \%$, and purge time of $60 \mathrm{~s}$. The residual solids were separated from the extraction, and then lyophilized overnight by freeze-dryer to extract out the lipid-free or polysaccharidesfree algae detritus for further absorptive study. Each additive amount of the algal fractions in the adsorption experiments was also $4 \mathrm{~g} \mathrm{~L}^{-1}$.

\subsection{In-situ observation}

A laser scanning confocal microscope (LCSM, Olympus Fluoview FV1000) with a $40 \times$ objective lens was applied to observe the algae samples to visualize the adsorption of PAHs on U. prolifera detritus. The LCSM wavelength was set at $405 \mathrm{~nm}$. Images of PAHs in/on the tissues of $U$. prolifera detritus were inspected and processed by the Viewer software (FV10-ASW 2.1c).

\subsection{Desorption tests}

Desorption tests were conducted to assess the potential release of contaminants from the detritus of algae. The exhausted $U$. prolifera detritus was collected after filtration from the kinetic tests. Thereafter, a known weight of detritus was placed in seawater without PAHs. At given time intervals, samples were collected until the concentrations of PAHs in the solution became constant. The desorption rate (Eq. (9)) was calculated based on the final concentration of PAHs in desorption medium and the initially amounts of PAHs adsorbed on the U. prolifera detritus:

Desoprtion $(\%)=\frac{\text { Released PAHs }}{\text { Initially sorbed PAHs }} \times 100 \%$

\subsection{Analytical methods}

The PAHs samples were detected by a ACQUITY UPLC system (Waters, Milford, USA) equipped with a C18 reverse phase column (2.1 $\times 50 \mathrm{~mm}, 1.7 \mu \mathrm{m})$. The mobile phase was $\mathrm{H}_{2} \mathrm{O}$ /acetonitrile $(20 / 80, \mathrm{v} / \mathrm{v}$ $\%$ ) and the flow rate was $0.2 \mathrm{~mL} \mathrm{~min}^{-1}$. The fluorescence of eluted compounds was monitored at $\lambda_{\text {ex }} 224 \mathrm{~nm} / \lambda_{\mathrm{em}} 325 \mathrm{~nm}, \lambda_{\mathrm{ex}} 242 \mathrm{~nm} / \lambda_{\mathrm{em}}$ $360 \mathrm{~nm}$, and $\lambda_{\text {ex }} 285 \mathrm{~nm} / \lambda_{\mathrm{em}} 410 \mathrm{~nm}$ for Naph, Phe and BaP, respectively, using a fluorescence detector (Waters, Milford, USA). The injection volume was $10 \mu \mathrm{L}$. The detection limits for Naph, Phe and BaP were $0.3 \mu \mathrm{g} \mathrm{L}^{-1}, 0.3 \mu \mathrm{g} \mathrm{L}^{-1}$ and $0.1 \mu \mathrm{g} \mathrm{L}-1$, respectively. The method recoveries ranged from $95 \%$ to $98 \%$ while the RSD values were in the range of $0.1 \%-0.2 \%$ to meet the detection requirements. All experiments were conducted in triplicate. The results were analyzed by Origin 8.5 and SPSS 20.0. One-way ANOVA and the $t$-test were employed to compare the differences of the PAHs removal efficiency under various treatments. The significance level was considered as $\mathrm{p}<0.05$. 


\section{Results and discussion}

\subsection{Adsorptive removal of PAHs}

Fig. 1a shows the change of adsorbed PAHs (Naph, Phe and BaP) as a function of contact time. The detritus biomass adsorbed up to 51\%, 79\%, and $99 \%$ of the total amount of Naph, Phe, and BaP at initial concentration of $10 \mu \mathrm{g} \mathrm{L}^{-1}$ within $24 \mathrm{~h}$. All the plots showed the same general features of a very rapid initial stage followed by a longer period of much slower uptake. Amount of adsorbed target PAHs increased rapidly until the contact time reached $2 \mathrm{~h}$ for $\mathrm{BaP}, 6 \mathrm{~h}$ for Phe, and $10 \mathrm{~h}$ for Naph, indicating that Naph needed more time to reach equilibrium than Phe and BaP. After this quick step, the adsorption rate became slower and no further significant adsorption was observed beyond $24 \mathrm{~h}$. The loss of PAHs during adsorptive test without the detritus was $<8 \%$ while no additional PAHs were introduced into the adsorptive systems by the $U$. prolifera detritus according to the results of blank adsorptive experiments, confirming that the target PAHs were mainly removed through the adsorption in the presence of detritus of green tidal algae. The results showed that equilibrium adsorptive capacities of Naph, Phe and BaP on the U. prolifera detritus were $1.27,1.97$, and $2.49 \mathrm{mg} \mathrm{kg}^{-1}$, respectively. The fluorescence of PAHs was clearly observed based on the LCSM images to show the accumulation of PAHs on the detritus of $U$. prolifera (Fig. 2), reconfirming the adsorption of PAHs on $U$. prolifera detritus. A few studies also demonstrated that algal biomass was capable of accumulating PAH compounds by
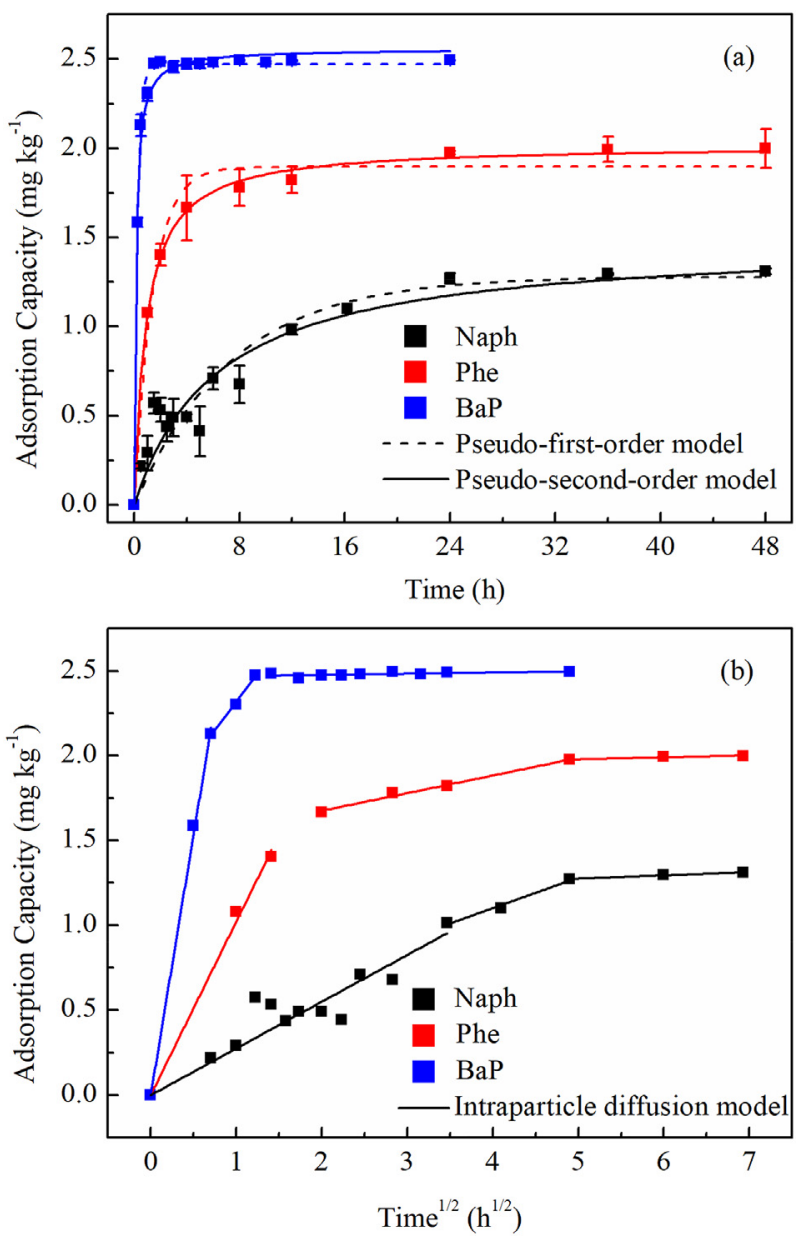

Fig. 1. Adsorptive kinetics of naphthalene (Naph), phenanthrene (Phe) and benzo[a] pyrene (BaP) on the detritus of Ulva prolifera. (a) Pseudo-first-order and pseudosecond-order model, and (b) intraparticle diffusion model fitting curves of the experimental data. adsorptive processes (Chen et al., 2011; Christensen and Rorrer, 2009; Zhang et al., 2013a).

The kinetic data fitted better with pseudo-second-order model $\left(R^{2}\right.$ values ranged from 0.9072 to 0.9977 ) than pseudo-first-order model $\left(R^{2}\right.$ values ranged from 0.8609 to 0.9928 ) (Fig. 1a), suggesting that the adsorption process might be chemisorption. This was consistent with other reports on the adsorptive kinetics of typical PAHs on the dead tissue of brown seaweed Sargassum hemiphyllum (Chung et al., 2007). Although the pseudo-second-order model described the reaction kinetics well, it is confined in accuracy by considering adsorption as a one-step binding process (Ren et al., 2012). The intraparticle diffusion model could demonstrate comprehensive view of the adsorption process with several distinct steps (D'Arcy et al., 2011). Fig. 1b presented the plots of $\mathrm{q}_{\mathrm{t}}$ against $\mathrm{t}^{1 / 2}$ based on intraparticle diffusion model. It clearly showed three linear sections and this multi-linearity further indicated the complexity of the adsorption process. The first linear portion was a fast stage. This could be caused by the quick transfer of PAHs from bulk phase to detritus surface. The second linear section was a moderate adsorption process during which the rate of adsorption was governed by the intraparticle diffusion in the pore structure. The third linear step was final equilibrium. The intraparticle diffusion is the only rate controlling process if the line passes through the origin, otherwise external mass transfer controls the adsorption to some degree ( $\mathrm{Li}$ and Zhang, 2017). Interestingly, only the first stage passed through the origin while the others did not according to Fig. $1 \mathrm{~b}$. Therefore, it could be deduced that except for chemical non-equilibrium, intraparticle diffusion was also involved in the sorption processes of PAHs. Additionally, the value of the intercept $C$ in the second section provides information related to the boundary layer thickness (Boparai et al., 2011). The larger intercepts indicate the larger role of the surface diffusion as the ratelimiting step. The intercept values of this study increased as the following: $\mathrm{BaP}>\mathrm{Phe}>\mathrm{Naph}$, which suggested that the surface diffusion became more important as their hydrophobicity increasing.

\subsection{Effects of detritus fractions on the adsorption of PAHs}

Algal biomass has many functional groups such as carboxyl, hydroxyl and sulphate groups that are generated by their complex polysaccharides, protein and lipid components (Sarı and Tuzen, 2008a), which suggests that the adsorption process may be affected by these algal detritus fractions. This study evaluated the contributions of lipid and polysaccharides fraction of algal detritus on adsorptive removal of PAHs to better understand the interaction behavior between the detritus and contaminants. After the removal of the lipid fractions, the adsorption capacity of BaP, Phe, and Naph reduced by $25 \%, 23 \%$, and $8 \%$, respectively (Fig. 3). Clearly, the lipid fractions played an important role in the adsorption of PAHs. The adsorption capacity of Phe and BaP reduced slightly after the removal of polysaccharides, implying that polysaccharides might be of less effect on Phe and $\mathrm{BaP}$ removal process. However, the adsorption capacity of Naph increased by $57 \%$ after polysaccharides removal. A rational explanation is related to the change in composition and structure of $U$. prolifera detritus and the nature property of pollutants. After removal of polysaccharides fraction, the formation of more and/or larger pores on the detritus was in favor of the intraparticle diffusion of pollutants with lower hydrophobicity, which led to the sharp increase in the adsorption capacity of Naph.

\subsection{Effect of salinity and $\mathrm{pH}$ on PAHs adsorptive removal}

The coastal environments could be subjected to fluctuations in environmental variables such as salinity and $\mathrm{pH}$, which may alter the adsorptive removal of organic pollutant on U. prolifera detritus. In this study, a salinity gradient representing estuarine and marine conditions, with salinities corresponding to 16,24 and $32 \mathrm{~g} \mathrm{~L}^{-1}$ was evaluated. Fig. 4a showed the effect of salinity on the removal of the three PAHs by detritus of $U$. prolifera. The equilibrium removal capacities of the 

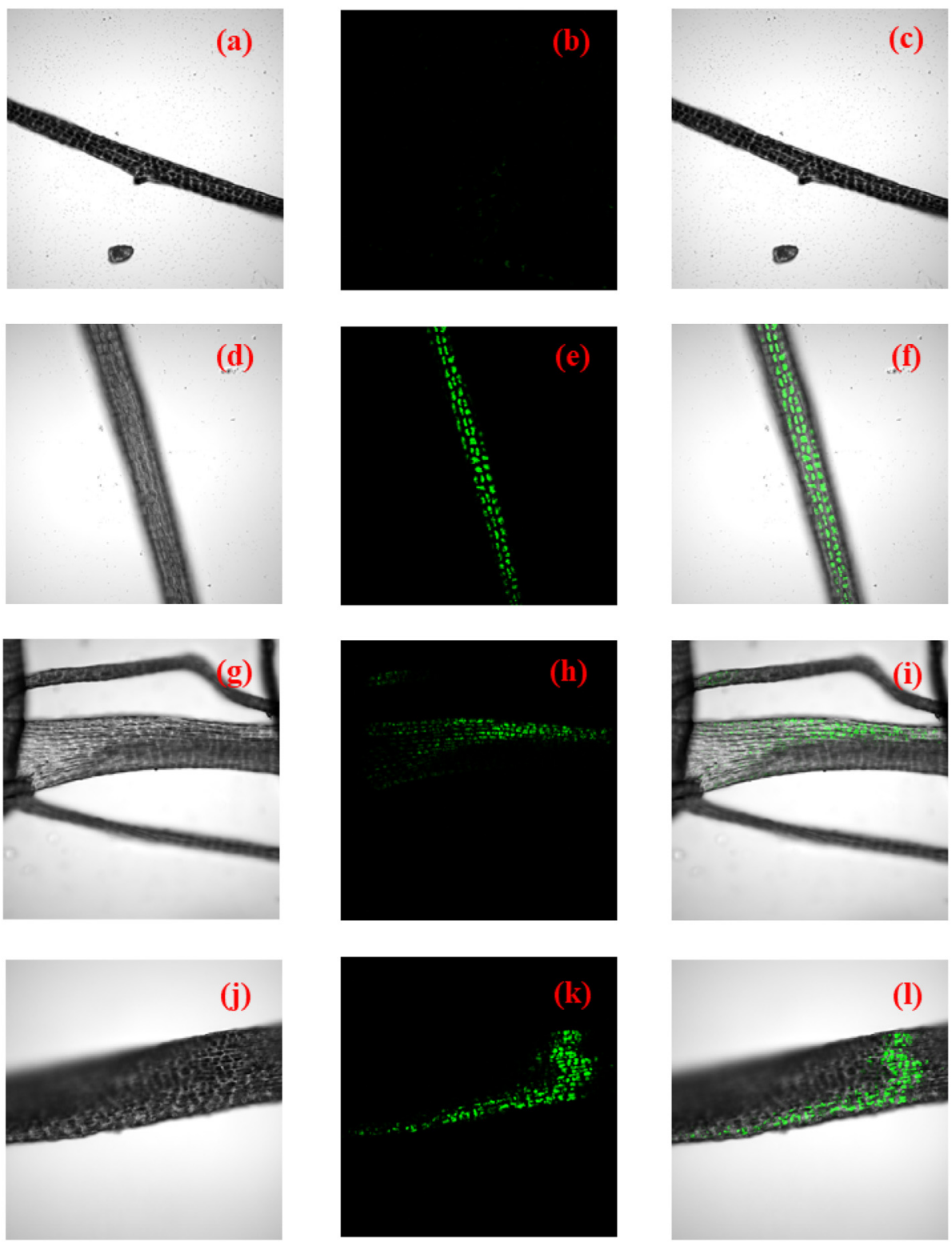

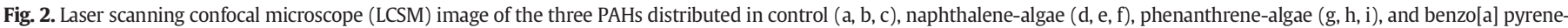
algae $(j, k, l)$ under brightfield image $(a, d, g, j)$, green fluorescence image $(b, e, h, k)$ and overlay image $(c, f, i, 1)\left(\times 10, \lambda_{\text {ex }}=405 \mathrm{~nm}\right)$.

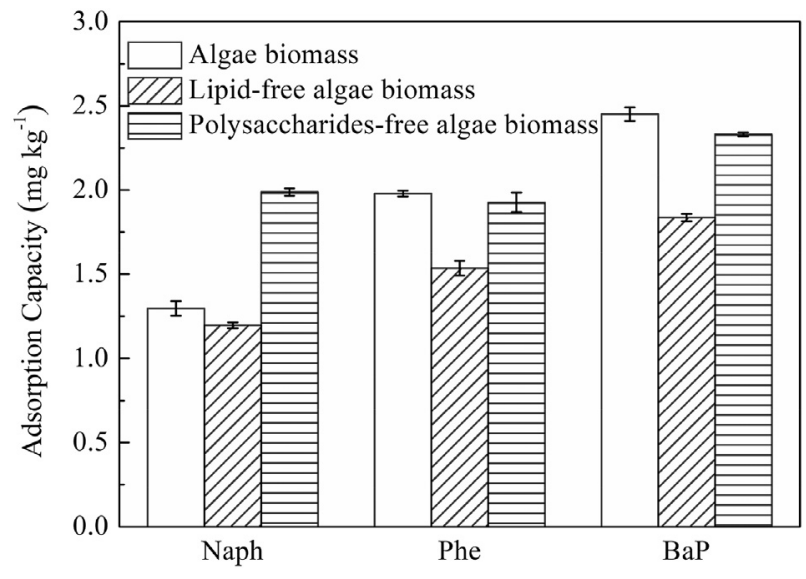

Fig. 3. The influence of the lipid and polysaccharides fraction of the detritus of Ulva prolifera on the adsorptive removal of naphthalene (Naph), phenanthrene (Phe) and benzo[a] pyrene $(\mathrm{BaP})$.
PHE and BaP were similar among the treatments. In contrast, a threefold increase in the adsorption capacity of $\mathrm{NaP}$ was observed when the salinity increased from 16 to $32 \mathrm{~g} \mathrm{~L}^{-1}$. One reasonable explanation for the increase might be the salting-out effect that leads to the reduced solubility of organic compounds (Lu et al., 2017).

The adsorptive capacity of $U$. prolifera detritus for Naph and Phe exhibited a similar variation as $\mathrm{pH}$ increased from 5.0 to 8.0 and thereafter decreased sharply with further increased pH (Fig. 4b). The maximum equilibrium adsorptive capacity for Naph and Phe was determined as 1.27 and $2.02 \mathrm{mg} \mathrm{kg}^{-1}$ at $\mathrm{pH} 8.0$, respectively. No significant variations for BaP removal were observed under various initial $\mathrm{pH}$ (5.0-9.0), while constant alkalinity resulted in an alleviated sorption by detritus. Since the $\mathrm{pH}$ of wastewater discharged into coastal area usually ranged from 5.5 to 9.0 (Lu et al., 2017), the influence of pH fluctuation on the adsorption of $\mathrm{BaP}$ by the algal detritus can be neglected in most cases. Similar results were obtained by Chung et al. (Chung et al., 2007) who found that the equilibrium removal capacities for Phe by Sargassum hemiphyllum (brown seaweed) were higher under treatments around neutral. It is well known that pH could affect the protonation of the 

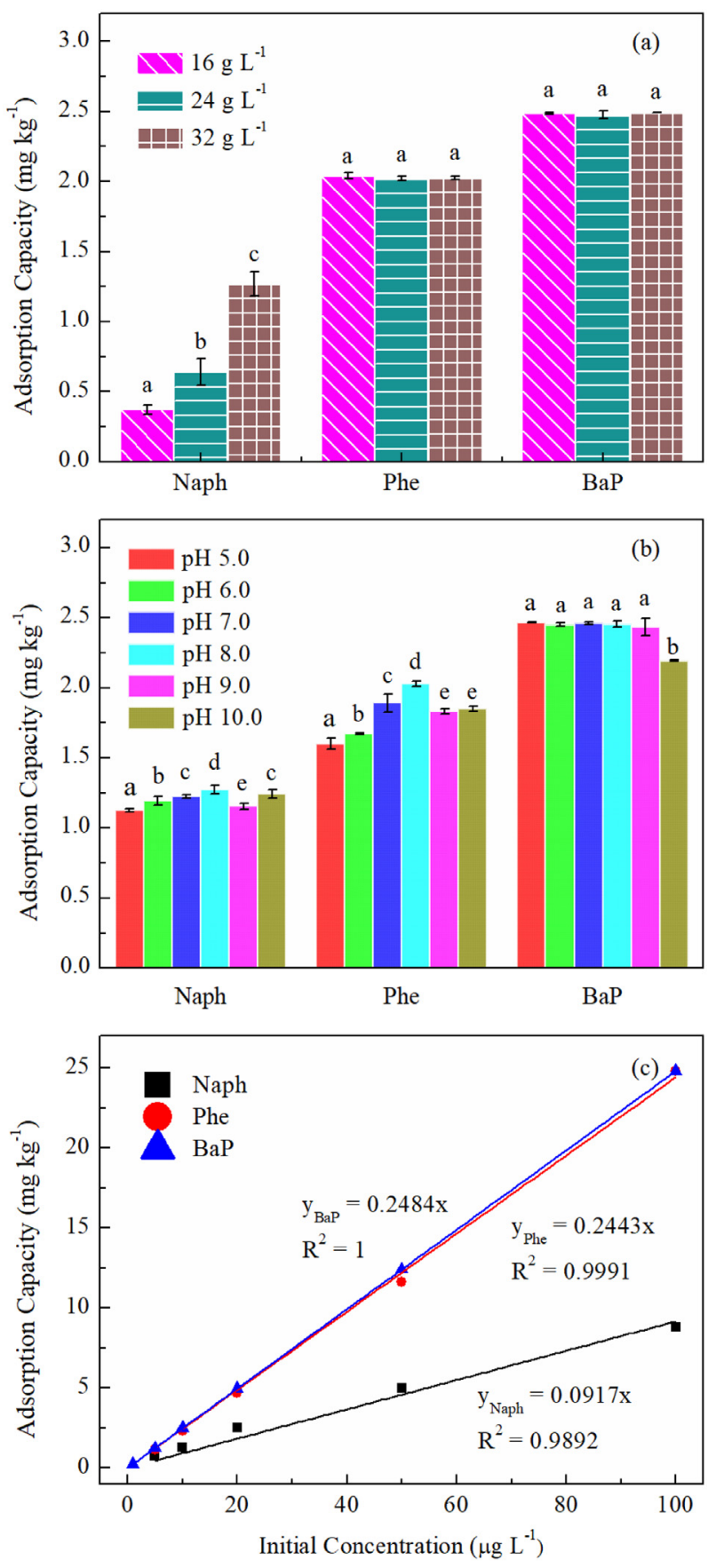

Fig. 4. Effects of (a) salinity, (b) $\mathrm{pH}$ and (c) initial concentration on the removal of naphthalene (Naph), phenanthrene (Phe), and benzo[a] pyrene (BaP) by Ulva prolifera detritus. Groups sharing the same letter within each treatment are not significantly different as classified by one-way ANOVA test $(\mathrm{p}<0.05)$.

functional groups on the algal biomass. The cell wall ligands were protonated at low $\mathrm{pH}$ while they carried negative charges at relatively high pH (Gupta and Rastogi, 2008). The ligands carried less charges around neutral since PAHs are non-polar and non-ionizable aromatic compounds, which subsequently led to relatively high PAHs adsorption capacity.

\subsection{Effect of initial concentration of PAHs}

The initial concentration could provide essential driving force to overcome the mass transfer resistances of the pollutants between the aqueous and solid phases (Vijayaraghavan et al., 2008). Therefore, a higher initial concentration of contaminants will promote the adsorption process. The equilibrium sorption capacity as a function of the initial concentration was shown in Fig. 4c. The increase in the initial concentration of PAHs led to the increase in the equilibrium sorption capacity of the detritus. A linear relationship $\left(R^{2} \geq 0.9892\right)$ between initial concentration and the adsorption capacity maintained even at relative high concentrations (up to $100 \mu \mathrm{g} \mathrm{L}^{-1}$ ), indicating the potential high PAHs removal capacity of $U$. prolifera detritus in coastal sediment during the end of green tides.

Partition coefficient $\left(\mathrm{K}_{\mathrm{d}}\right)$ is an effective parameter for estimating the distribution of target pollutants between two phases, which could have great influence on the fate and mobility of contaminants in the environment (Chung et al., 2007). The detritus-water partition coefficient $\left(K_{d w}\right)$ was calculated as $0.14 \mathrm{Lg}^{-1}$ for Naph, $2.89 \mathrm{Lg}^{-1}$ for Phe, and $34.68 \mathrm{Lg}^{-1}$ for BaP. Considering that Naph $\left(\log K_{o w}=3.37\right)$, Phe $\left(\log K_{o w}=4.57\right)$, and $\mathrm{BaP}\left(\log K_{o w}=5.91\right)$ possess 10 times difference in their octanolwater partitioning constant $\left(K_{o w}\right)$, PAH compounds were preferentially partitioning into the lipophilic biomass constituents of the detritus. Some related work was also conducted to estimate partitioning constants of PAHs for marine algae. Christensen and Rorrer (Christensen and Rorrer, 2009) reported that the predicted $K_{d}$ based on lipid content was $0.093 \mathrm{~L}(\mathrm{~g} \mathrm{DW})^{-1}$ for Naph and $1.5 \mathrm{~L}(\mathrm{~g} \mathrm{DW})^{-1}$ for Phe, respectively. Whereas Zhang et al. (Zhang et al., 2013a) reported that the Phe partitioning constant for three market algal species (Spirulina, Seaweed, Porphyra) were from 0.91 to $1.47 \mu \mathrm{g} \mathrm{OC}^{-1} /\left(\mu \mathrm{g} \mathrm{L}^{-1}\right)$.

\subsection{Adsorption isotherms}

The Freundlich model fitted the experimental data well with high correlation coefficients ( $R^{2}$ values ranged from 0.9633 to 0.9997 ) (Fig. 5) and the equilibrium isotherm for all three PAHs were linear $(1 / n=1)$, indicating that the primary mechanism of sorption was partitioning into algae detritus. $\mathrm{K}_{\mathrm{F}}$, one of the Freundlich constants, is an indicator for the adsorption capacity, while n, the other Freundlich constant relating to adsorption intensity, has a lower value in the case of more heterogeneous surfaces (Sarı and Tuzen, 2008b). The values of $\mathrm{K}_{\mathrm{F}}$ decreased with the rise in temperature from $10{ }^{\circ} \mathrm{C}$ to $30{ }^{\circ} \mathrm{C}$ for Naph and Phe (Fig. 5 inset). The maximum adsorptive capacity of PAHs by the detritus was determined as 21.04 and $23.60 \mathrm{mg} \mathrm{kg}^{-1}$ for Naph and Phe at $10{ }^{\circ} \mathrm{C}$, respectively. The adsorptive capacity decreased with increasing temperature, which indicated that the adsorptive process was exothermic in nature. Conversely, higher temperature was beneficial for $\mathrm{BaP}$ removal by detritus biomass, and the maximum adsorption capacity was determined as $24.75 \mu \mathrm{L} \mathrm{L}^{-1}$ at $20^{\circ} \mathrm{C}$. The obtained values of $\mathrm{n}$ indicated a high adsorption ability of each PAH by detritus at all temperatures. This observation is consistent with the previous report on cultured algae and market algae biomasses (Zhang et al., 2013a). The isotherms of the three PAHs showed no obvious saturation over the PAHs concentration (Naph and Phe: 5-100 $\mu \mathrm{g} \mathrm{L}^{-1}$, BaP: $1-100 \mu \mathrm{g} \mathrm{L}^{-1}$ ) and temperature ranges $\left(10-30^{\circ} \mathrm{C}\right)$, indicating that a complete monolayer of PAHs covering on the surface of $U$. prolifera detritus was not formed.

\subsection{Desorption}

Desorption results which followed the adsorption were shown in Fig. 6. The total amounts of desorption of Naph, Phe and BaP from algal detritus to the aqueous phase were $16.26,19.36$, and $0.18 \mathrm{ng}$, respectively, while the desorption rates were about $16 \%, 12 \%$, and $0.1 \%$ of their amounts of sorption, respectively. The low desorption rates of PAHs indicated the strong bonding between the adsorbed PAHs and the sportive sites on the algal detritus. Low desorption rates of PAHs in adsorption-desorption system was also observed in previous studies (Kan et al., 2000; Oh et al., 2013; Yang et al., 2013). PAHs with higher hydrophobicity and low solubility in 


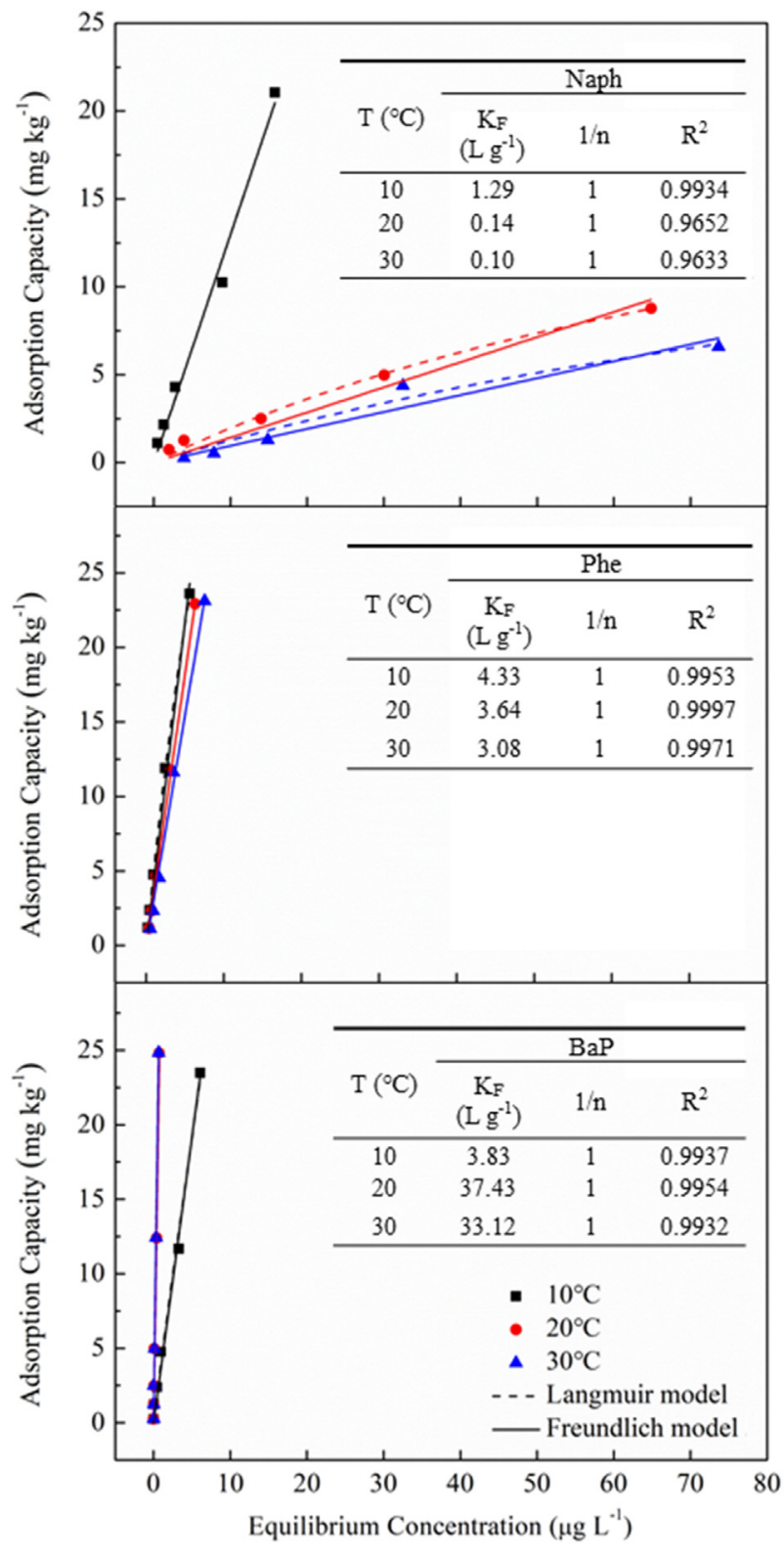

Fig. 5. Adsorptive isotherms of naphthalene (Naph), phenanthrene (Phe) and benzo[a] pyrene (BaP) on the detritus of $U$. prolifera at different temperature. Inset: Freundlich adsorption isotherm constants for the adsorption of the PAHs by non-viable biomass of U. prolifera at different temperature.

water are more strongly adsorbed onto the organic matters so as to reside in the desorption-resistant fraction in the coastal environment (Oh et al., 2013). The kinetics of PAHs desorption were generally well described by the pseudo-first-order kinetic model $\left(R^{2}\right.$ values ranged from 0.9446 to 0.9827 ), suggesting that the mechanism of desorption process was quite different with that of the adsorption process followed a pseudo-second-order kinetics. Desorption kinetic results demonstrated the extremely slow desorption process. More than $85 \%$ of the irreversibly sorbed compounds was tightly trapped while the subsequently desorption was extremely slow, which provided a new natural remediation approach to support the assumption that no substantial risk to health or the environment will be added if trace level tightly-bound contaminants are left in the algal detritus. The irreversibly sorbed chemicals are commonly considered 'benign' to the environment (Kan et al., 2000).
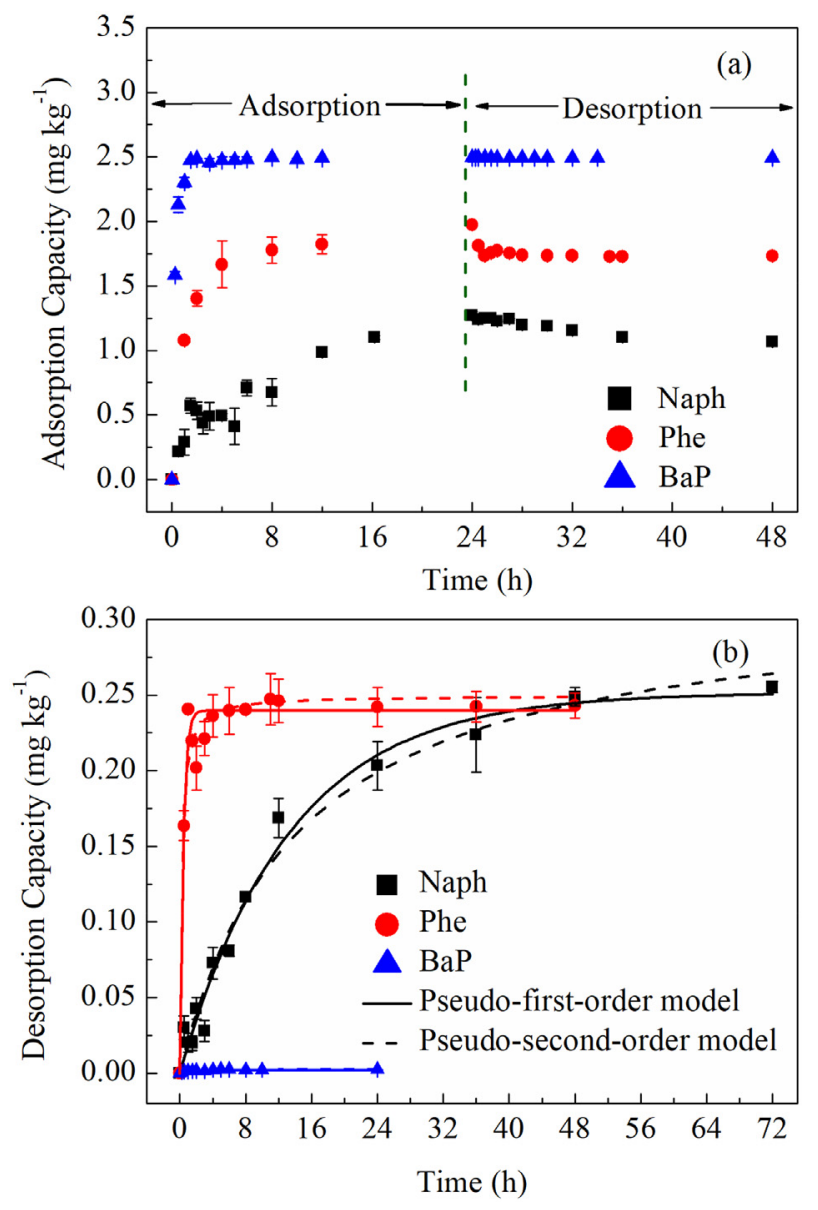

Fig. 6. (a) The adsorption-desorption dynamic curves of naphthalene (Naph), phenanthrene (Phe) and benzo[a] pyrene (BaP) on the detritus of Ulva prolifera and (b) Pseudo-first-order and pseudo-second-order kinetic equations fitting curves of the desorptive experimental data.

\section{Conclusions}

The adsorptive removal of selected polycyclic aromatic hydrocarbon by detritus of harmful green tide algae deposited in coastal sediment was firstly investigated. The three target PAHs were quickly adsorbed on the detritus following a pseudo-second-order kinetics. The adsorption isotherm fitted well with the Freundlich model. The lipid fraction of the algal detritus was of importance on the adsorptive removal of PAHs. The removal efficiency by U. prolifera maintained a linear relationship with initial concentration of PAHs even at $100 \mu \mathrm{g} \mathrm{L}^{-1}$ which was much higher than the environmentally relevant concentrations. Desorption of PAHs on the algal detritus followed pseudo-first-order adsorption kinetics. The extremely low desorption rate suggested that PAHs were tightly trapped in the detritus of green tidal algae. Given the deposition of huge amounts of $U$. prolifera detritus in coastal sediments during the occurrence of green tide, the algal detritus could be a significant contributor for removing PAHs. These findings indicated that the deposition of the detritus of algae during the outbreak of green tide algae might provide a new natural remediation for PAHs contamination in coastal sediments in the terms of the efficient adsorptive removal by detritus of green tidal algae.

\section{Acknowledgements}

This work was financially supported by National Natural Science Foundation of China (41671319), One Hundred Talents Program of Chinese Academy of Sciences (Y629041021), Taishan Scholar Program of 
Shandong Province (No. tsqn201812116), Two-Hundred Talents Plan of Yantai (Y739011021), and Research Program of CAS Key Laboratory of Coastal Environmental Processes and Ecological Remediation (No. 1189010002).

\section{References}

Arias, A.H., Souissi, A., Glippa, O., Roussin, M., Dumoulin, D., Net, S., Ouddane, B., Souissi, S. 2017. Removal and biodegradation of phenanthrene, fluoranthene and pyrene by the marine algae Rhodomonas baltica enriched from North Atlantic coasts. Bull. Environ. Contam. Toxicol. 98, 392-399.

Bakir, A., Rowland, S.J., Thompson, R.C., 2014. Transport of persistent organic pollutants by microplastics in estuarine conditions. Estuar. Coast. Shelf Sci. 140, 14-21.

Bhattacharya, P., Lin, S., Turner, J.P., Ke, P.C., 2010. Physical adsorption of charged plastic nanoparticles affects algal photosynthesis. J. Phys. Chem. C 114, 16556-16561.

Boparai, H.K., Joseph, M., O'Carroll, D.M., 2011. Kinetics and thermodynamics of cadmium ion removal by adsorption onto nano zerovalent iron particles. J. Hazard. Mater. 186, 458-465.

Bulgariu, D., Bulgariu, L., 2012. Equilibrium and kinetics studies of heavy metal ions biosorption on green algae waste biomass. Bioresour. Technol. 103, 489-493.

Chen, B., Yuan, M., Liu, H., 2011. Removal of polycyclic aromatic hydrocarbons from aqueous solution using plant residue materials as a biosorbent. J. Hazard. Mater. 188, 436-442.

Christensen, K.M., Rorrer, G.L., 2009. Equilibrium partitioning behavior of naphthalene and phenanthrene with axenic microplantlets of the temperate green seaweed Acrosiphonia coalita. Chemosphere 76, 1135-1142.

Chung, M.K., Tsui, M.T.K., Cheung, K.C., Tam, N.F.Y., Wong, M.H., 2007. Removal of aqueous phenanthrene by brown seaweed Sargassum hemiphyllum: sorption-kinetic and equilibrium studies. Sep. Purif. Technol. 54, 355-362.

D'Arcy, M., Weiss, D., Bluck, M., Vilar, R., 2011. Adsorption kinetics, capacity and mechanism of arsenate and phosphate on a bifunctional $\mathrm{TiO}_{2}-\mathrm{Fe}_{2} \mathrm{O}_{3}$ bi-composite. Springerplus 4, 1-7.

Fan, X., Xu, D., Wang, Y., Zhang, X., Cao, S., Mou, S., Ye, N., 2014. The effect of nutrient concentrations, nutrient ratios and temperature on photosynthesis and nutrient uptake by Ulva prolifera: implications for the explosion in green tides. J. Appl. Phycol. 26, 537-544.

Gao, F., Peng, Y., Li, C., Yang, G., Deng, Y., Xue, B., Guo, Y., 2018. Simultaneous nutrient removal and biomass/lipid production by Chlorella $s p$. in seafood processing wastewater. Sci. Total Environ. 640-641, 943-953.

Gupta, V.K., Rastogi, A., 2008. Biosorption of lead from aqueous solutions by green algae Spirogyra species: kinetics and equilibrium studies. J. Hazard. Mater. 152, 407-414.

Kan, A.T., Chen, W., Tomson, M.B., 2000. Desorption kinetics of neutral hydrophobic organic compounds from field-contaminated sediment. Environ. Pollut. 108, 81-89.

Khuman, S.N., Chakraborty, P., Cincinelli, A., Snow, D., Kumar, B., 2018. Polycyclic aromatic hydrocarbons in surface waters and riverine sediments of the Hooghly and Brahmaputra Rivers in the Eastern and Northeastern India. Sci. Total Environ. 636, 751-760.

Li, J., Zhang, H., 2017. Factors influencing adsorption and desorption of trimethoprim on marine sediments: mechanisms and kinetics. Environ. Sci. Pollut. Res. 1-9.

Li, H., Zhang, Y., Han, X., Shi, X., Rivkin, R.B., Legendre, L., 2016. Growth responses of Ulva prolifera to inorganic and organic nutrients: implications for macroalgal blooms in the southern Yellow Sea, China. Sci. Rep. 6.

Liu, X., Li, Y., Wang, Z., Zhang, Q., Cai, X., 2015. Cruise observation of Ulva prolifera bloom in the southern Yellow Sea, China. Estuar. Coast. Shelf Sci. 163, 17-22.

Lu, J., Zhang, C., Wu, J., Luo, Y., 2017. Adsorptive removal of bisphenol A using N-doped biochar made of Ulva Prolifera. Water Air Soil Pollut. 228, 327.

Luo, M.B., Liu, F., Xu, Z.L., 2012. Growth and nutrient uptake capacity of two co-occurring species, Ulva prolifera and Ulva linza. Aquat. Bot. 100, 18-24.

Luo, L., Wang, P., Lin, L., Luan, T., Ke, L., Tam, N.F.Y., 2014. Removal and transformation of high molecular weight polycyclic aromatic hydrocarbons in water by live and dead microalgae. Process Biochem. 49, 1723-1732.
Oh, S., Wang, Q., Shin, W.S., Song, D.I., 2013. Sorption and desorption kinetics of PAHs in coastal sediment. Korean J. Chem. Eng. 30, 145-153.

Pieber, S., Schober, S., Mittelbach, M., 2012. Pressurized fluid extraction of polyunsaturated fatty acids from the microalga Nannochloropsis oculata. Biomass Bioenergy 47, 474-482.

Ren, Z.M., Shao, L.N., Zhang, G.S., 2012. Adsorption of phosphate from aqueous solution using an iron-zirconium binary oxide sorbent. Water Air Soil Pollut. 223, 4221-4231.

Sarı, A Tuzen, M. 2008a. Biosorption of cadmium(II) from aqueous solution by red algae (Ceramium virgatum): equilibrium, kinetic and thermodynamic studies. J. Hazard. Mater. 157, 448-454.

Sarı, A., Tuzen, M., 2008b. Biosorption of total chromium from aqueous solution by red algae (Ceramium virgatum): equilibrium, kinetic and thermodynamic studies. J. Hazard. Mater. 160, 349-355.

Son, E.-B., Poo, K.-M., Chang, J.-S., Chae, K.-J., 2018. Heavy metal removal from aqueous solutions using engineered magnetic biochars derived from waste marine macro-algal biomass. Sci. Total Environ. 615, 161-168.

Sun, K.-M., Li, R., Li, Y., Xin, M., Xiao, J., Wang, Z., Tang, X., Pang, M., 2015. Responses of Ulva prolifera to short-term nutrient enrichment under light and dark conditions. Estuar. Coast. Shelf Sci. 163, 56-62.

Sun, R., Sun, Y., Li, Q.X., Zheng, X., Luo, X., Mai, B., 2018. Polycyclic aromatic hydrocarbons in sediments and marine organisms: implications of anthropogenic effects on the coastal environment. Sci. Total Environ. 640-641, 264-272.

Turner, J.T., 2015. Zooplankton fecal pellets, marine snow, phytodetritus and the ocean's biological pump. Prog. Oceanogr. 130, 205-248.

Vijayaraghavan, K., Won, S.W., Mao, J., Yun, Y.-S., 2008. Chemical modification of Corynebacterium glutamicum to improve methylene blue biosorption. Chem. Eng. J. 145, 1-6.

Wen, Q., Chen, Z., Lian, J., Feng, Y., Ren, N., 2012. Removal of nitrobenzene from aqueous solution by a novel lipoid adsorption material (LAM). J. Hazard. Mater. 209-210, 226-232.

Wen, X., Feng, Q., Lu, J., Wu, J., Wu, M., Guo, X., 2017. Risk assessment and source identification of coastal groundwater nitrate in northern China using dual nitrate isotopes combined with Bayesian mixing model. Hum. Ecol. Risk. Assess. 1-15.

Xiong, Y., Xu, J., Shan, W., Lou, Z., Fang, D., Zang, S., Han, G., 2013. A new approach for rhenium(VII) recovery by using modified brown algae Laminaria japonica adsorbent. Bioresour. Technol. 127, 464-472.

Yang, L., Chen, J.P., 2008. Biosorption of hexavalent chromium onto raw and chemically modified Sargassum sp. Bioresour. Technol. 99, 297-307.

Yang, L., Jin, M., Tong, C., Xie, S., 2013. Study of dynamic sorption and desorption of polycyclic aromatic hydrocarbons in silty-clay soil. J. Hazard. Mater. 244-245, 77-85.

Yuan, M., Tong, S., Zhao, S., Jia, C.Q., 2010. Adsorption of polycyclic aromatic hydrocarbons from water using petroleum coke-derived porous carbon. J. Hazard. Mater. 181, 1115-1120.

Zhang, D., Ran, C., Yang, Y., Ran, Y., 2013a. Biosorption of phenanthrene by pure algae and field-collected planktons and their fractions. Chemosphere 93, 61.

Zhang, J., Huo, Y., Zhang, Z., Yu, K., He, Q., Zhang, L., Yang, L., Xu, R., He, P., 2013b. Variations of morphology and photosynthetic performances of Ulva prolifera during the whole green tide blooming process in the Yellow Sea. Mar. Environ. Res. 92, 35-42.

Zhang, C., Lu, J., Wu, J., Luo, Y., 2017a. Removal of phenanthrene from coastal waters by green tide algae Ulva prolifera. Sci. Total Environ. 609, 1322-1328.

Zhang, D., Wang, J., Ni, H., Zeng, H., 2017b. Spatial-temporal and multi-media variations of polycyclic aromatic hydrocarbons in a highly urbanized river from South China. Sci. Total Environ. 581-582, 621-628.

Zhao, X., Qiu, H., Zhao, Y., Shen, J., Chen, Z., Chen, J., 2015. Distribution of polycyclic aromatic hydrocarbons in surface water from the upper reach of the Yellow River, Northwestern China. Environ. Sci. Pollut. Res. 22, 6950-6956.

Zhou, X., Feng, D., Wen, C., Liu, D., 2018. Decomposition dynamic of two aquatic macrophytes Trapa bispinosa Roxb. and Nelumbo nucifera detritus. Environ. Sci. Pollut. Res. 25, 16177-16191. 